\title{
Budget Impact of Enzalutamide for Chemotherapy-Naïve Metastatic Castration-Resistant Prostate Cancer
}

\author{
Cat N. Bui, PharmD, MS; Ken O’Day, PhD, MPA; Scott Flanders, PhD; Nina Oestreicher, PhD; \\ Peter Francis, MD; Linda Posta, PharmD, MBA; Breanna Popelar, PharmD, MS; \\ Hong Tang, MD, FACP; and Mark Balk, PharmD, MS, BCPS
}

\section{ABSTRACT}

BACKGROUND: Prostate cancer is expected to account for approximately one quarter of all new diagnoses of cancer in American men in 2015. The cost of prostate cancer care is expected to reach $\$ 15.1$ billion by the year 2020 , up from $\$ 11.9$ billion in 2010 . Given the high burden of prostate cancer, health care payers are interested in quantifying the potential budget impact of new therapies.

OBJECTIVE: To estimate the budget impact of enzalutamide for the treatment of chemotherapy-naive metastatic castration-resistant prostate cancer (MCRPC) from a U.S. payer perspective.

METHODS: A model was developed to assess the budget impact of enzalutamide for treatment of chemotherapy-naïve MCRPC patients in a hypothetical 1-million-member U.S. health plan over a 1-year time horizon. Comparators included abiraterone acetate, sipuleucel-T, radium Ra 223 dichloride, and docetaxel. Epidemiologic data, including National Cancer Institute Surveillance, Epidemiology, and End Results (SEER) incidence rates, were used to estimate the number of chemotherapy-naïve mCRPC patients. Dosing, administration, duration of therapy, and adverse event rates were based on package inserts and pivotal studies. Drug costs were obtained from RED B00K and Centers for Medicare \& Medicaid Services (CMS) average sales price pricing files, costs of administration and monitoring from the CMS physician fee schedule, and adverse events from the Agency for Healthcare Research and Quality Healthcare Cost and Utilization Project and published literature. Market shares were estimated for each comparator before and after adoption of enzalutamide. The incremental aggregate budget impact, per patient per year (PPPY), per patient per month (PPPM), and per member per month (PMPM), was calculated. Oneway sensitivity analyses were performed.

RESULTS: In a population of 115 chemotherapy-naïve mCRPC patients, adopting enzalutamide had an annual incremental budget impact of \$510,641 (\$4,426 PPPY, \$369 PPPM, and \$0.04 PMPM). Results were most sensitive to enzalutamide drug cost, size of the chemotherapy-naïve mCRPC patient population, and enzalutamide adoption rate.

CONCLUSIONS: Results indicate a modest 1-year budget impact of adopting enzalutamide for chemotherapy-naïve MCRPC patients, partly because of the cost offset of a moderate incidence of adverse events and lack of additional required monitoring.

J Manag Care Spec Pharm. 2016;22(2):163-70

Copyright $\odot 2016$, Academy of Managed Care Pharmacy. All rights reserved.

\section{What is already known about this subject}

Prostate cancer is expected to account for approximately one quarter of all new diagnoses of cancer in American men in 2015. Prostate cancer is one of the most costly cancers in the United States, with prostate cancer-related costs totaling an estimated $\$ 11.9$ billion in 2010 ( $\$ 13.5$ billion in 2015 dollars).

Enzalutamide, an oral androgen receptor inhibitor that targets multiple steps within the androgen signaling pathway, represents a substantial advance in the treatment of metastatic castrationresistant prostate cancer (mCRPC).

\section{What this study adds}

We developed a model to estimate the budget impact of enzalutamide for the treatment of MCRPC patients who have not received chemotherapy (chemotherapy-naive patients). The model compares enzalutamide treatment with current treatment practice for the chemotherapy-naive patient population in accordance with National Comprehensive Cancer Network guidelines. In a hypothetical 1-million-member health plan, with a population of 115 chemotherapy-naive mCRPC patients, adopting enzalutamide had an annual incremental budget impact of $\$ 510,641$ or $\$ 0.04$ per member per month.

T $\mathrm{n}$ the United States, prostate cancer is the most common form of cancer in men and is expected to account for approximately one quarter of all new cancer diagnoses in men in 2015. ${ }^{1}$ An estimated 221,000 men in the United States will be diagnosed with prostate cancer in 2015. ${ }^{1}$ Clinical presentation varies depending on stage, ranging from early, localized disease to advanced, metastatic malignancies. ${ }^{2}$ Despite the high incidence of prostate cancer, the majority of patients (>95\%) do not progress to metastatic disease. ${ }^{3}$ Among patients who develop metastases, approximately 90\% have bone metastases and 57\% have visceral metastases. ${ }^{4}$ Patients with metastases are treated with androgen deprivation therapy to reduce testosterone to castrated levels. However, nearly all patients with metastases become castration resistant about 1-2 years after initiation of hormonal therapy. It is estimated that there will be approximately 27,540 deaths due to prostate cancer in $2015 .^{1}$ 


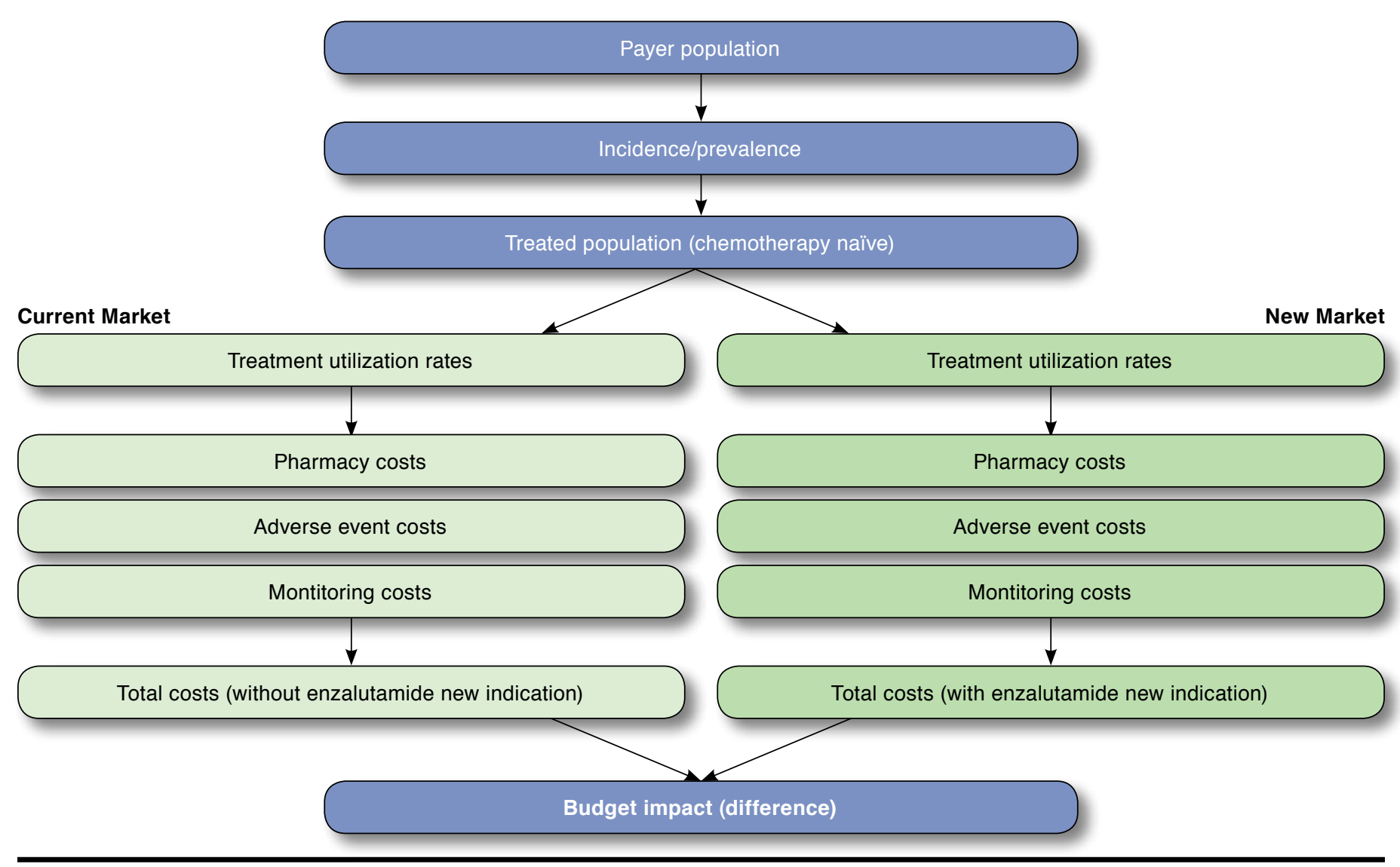

In addition to clinical impact, prostate cancer also carries a substantial economic burden. Prostate cancer-related costs totaled an estimated \$11.9 billion in 2010 ( $\$ 13.5$ billion in 2015 dollars), making prostate cancer one of the most costly cancers in the United States. ${ }^{5}$ Mean lifetime prostate cancer-related costs were estimated to total $\$ 34,432$ per patient in 2004 (\$48,963 in 2015 dollars). ${ }^{6}$ Average per patient per month (PPPM) prostate cancer-related costs in a commercial and Medicare Advantage U.S. population were estimated to be $\$ 1,799$ (standard deviation, $\$ 3,505)$ and comprised about half of all-cause health care costs for prostate cancer patients. ${ }^{7}$ With the advent of new prostate cancer therapies, it is important to understand the economic impact of their adoption in health plans.

The treatment landscape for metastatic castration-resistant prostate cancer (mCRPC) has been changing rapidly because of recent therapeutic advances. For patients with advanced mCRPC, first-line systemic therapy options include enzalutamide, abiraterone acetate, and docetaxel (category 1). ${ }^{8}$ Radium $\mathrm{Ra} 223$ dichloride is a first-line treatment for patients with symptomatic bone metastases (category 1$) .8$ Sipuleucel-T can also be used for first-line treatment of MCRPC, but should be limited to patients with good Eastern Cooperative Oncology Group performance status, estimated life expectancy of more than 6 months, no hepatic metastases, and no or minimal symptoms (category 1). ${ }^{8,9}$

Enzalutamide (Xtandi, Astellas Pharma U.S. and Medivation), an oral androgen receptor inhibitor that targets multiple steps within the androgen signaling pathway, represents an advancement in the treatment of mCRPC. ${ }^{10}$ The efficacy and safety of enzalutamide in men with $\mathrm{mCRPC}$ have been demonstrated in 2 randomized, placebo-controlled, multicenter phase 3 clinical trials. In the AFFIRM trial of MCRPC patients previously treated with docetaxel-based chemotherapy, enzalutamide demonstrated a statistically significant prolongation in median overall survival of 18.4 versus 13.6 months compared with placebo, resulting in a $37 \%$ reduction in risk of death (hazard ratio $[\mathrm{HR}]=0.63 ; 95 \%$ confidence interval $[\mathrm{CI}]=0.53-0.75$; $P<0.001)^{11}$

More recently, in the PREVAIL trial of chemotherapy-naive mCRPC patients whose disease progressed on androgen deprivation therapy, enzalutamide demonstrated statistically significant improvements in the 2 primary study endpoints 


\begin{tabular}{|c|c|c|c|}
\hline Parameter & $\begin{array}{c}\text { Age } \\
<65 \text { Years } \\
(\%)\end{array}$ & $\begin{array}{c}\text { Age } \\
\geq 65 \text { Years } \\
(\%)\end{array}$ & Source \\
\hline Plan population & 80.0 & 20.0 & Assumption \\
\hline Male & 49.2 & 49.2 & $\begin{array}{l}\text { Howden and Meyer } \\
2011 \text { (2010 U.S. Census) } 27\end{array}$ \\
\hline $\begin{array}{l}\text { Incidence of prostate } \\
\text { cancer }\end{array}$ & 0.057 & 0.713 & $\begin{array}{l}\text { Howlander et al. } \\
2014 \text { (SEER) }^{28}\end{array}$ \\
\hline With CRPC & 17.8 & 17.8 & Kirby et al. $2011^{29}$ \\
\hline $\begin{array}{l}\text { With metastatic disease } \\
\text { (chemotherapy-nailve) }\end{array}$ & 70.0 & 70.0 & $\begin{array}{l}\text { Nakabayashi et al. } \\
2013^{30}\end{array}$ \\
\hline
\end{tabular}

of overall survival $(23 \%$ reduction in risk of death; $P<0.001)$ and radiographic progression-free survival ( $81 \%$ reduction in risk of radiographic progression or death; $P<0.001) .{ }^{12,13}$ The median overall survival was 35.3 versus 31.3 months in the enzalutamide and placebo groups, respectively. ${ }^{13}$ The estimated median radiographic progression-free survival was 3.9 months in the placebo arm and was not reached in the enzalutamide group. ${ }^{12}$ Note that the study was stopped after a planned interim analysis, conducted when 540 deaths had been reported. ${ }^{12}$ Enzalutamide also demonstrated delay in the time to initiation of cytotoxic chemotherapy $(\mathrm{HR}=0.35 ; P<0.001)$ and median time to first skeletal-related event $(\mathrm{HR}=0.72 ; P<0.001) .{ }^{12}$

Health care decision makers are faced with a growing challenge of managing limited resources while optimizing patient outcomes, especially with regard to oncology products. As such, there is a need for clear, comprehensive information concerning the economic impact of new health technologies. To address this need, we developed a model to estimate the budget impact of enzalutamide for the treatment of MCRPC patients who have not received chemotherapy (chemotherapy-naive patients). The model compares enzalutamide treatment with current treatment practice for the chemotherapy-naive patient population in accordance with National Comprehensive Cancer Network guidelines. ${ }^{8}$ Comparators included enzalutamide, abiraterone acetate (Zytiga, Janssen Biotech), sipuleucel-T (Provenge, Dendreon), radium Ra 223 dichloride (Xofigo, Bayer HealthCare Pharmaceuticals), and docetaxel (Taxotere, Sanofi).

\section{Methods}

The model was developed from a U.S. third-party payer perspective. Costs in the model are intended to represent the treatment (pharmacy, administration, and pretreatment and concomitant medications), monitoring, and adverse event costs that would be incurred by the health care payer. Other disease-related costs (e.g., because of disease progression) and indirect costs (e.g., lost productivity) were not included in the model. A 1-year time horizon was used for the analysis and a hypothetical 1-million- member health plan was assumed. Figure 1 provides a schematic presentation of the budget impact model structure.

The model was developed based on National Comprehensive Cancer Network guidelines and recommendations from the Academy of Managed Care Pharmacy (AMCP) ${ }^{14}$ and the International Society for Pharmacoeconomics and Outcomes Research (ISPOR). ${ }^{15,16}$ Per AMCP and ISPOR guidelines, no discounting was used in the budget impact analysis.

\section{Model Assumptions}

The model included several key assumptions. For the hypothetical plan population, $80 \%$ of members were assumed to be aged younger than 65 years and 20\% of members were assumed to be aged 65 years or older. Oral drugs were assumed not to incur any administration costs. Costs for patients receiving sipuleucel-T or radium $\mathrm{Ra} 223$ dichloride were based on a full single-use vial; hence, any wastage was accounted for in the costs of these drugs. For patients receiving docetaxel, no wastage was included given the lower cost of this drug. For dosing purposes, average patient weight and body surface area were assumed to be $88 \mathrm{~kg}$ and $2.1 \mathrm{~m}^{2}$, respectively. ${ }^{17}$

Only grade 3 and 4 adverse events were included in the analysis. It was assumed that grade 3 and 4 events would require hospitalization based on the National Cancer Institute (NCI) Common Terminology Criteria for Adverse Events ${ }^{18}$ : grade 3 , severe or medically significant but not immediately life-threatening, hospitalization or prolongation of hospitalization indicated, disabling, limiting self-care activities of daily living; and grade 4, life-threatening consequences, urgent intervention indicated. Inclusion of pretreatment and concomitant medication was determined based on the prescribing information for the respective therapies. Inclusion of monitoring requirements was determined based on the prescribing information for the respective therapies. It should be noted that monitoring recommendations that affect only a small subpopulation of users were not included in the model (e.g., increased monitoring of international normalized ratio in patients receiving enzalutamide in combination with warfarin).

The model assumed a 9\% enzalutamide market adoption in the chemotherapy-naive population upon U.S. Food and Drug Administration (FDA) approval. New market shares for competitor products were based on the assumption that market adoption of enzalutamide corresponded with a reduction in market shares of other products in proportion to their current market share. Market shares were based on manufacturer internal market research.

\section{Model Inputs}

Target Population. The target population for the model was chemotherapy-naive adult patients diagnosed with mCRPC. The inputs utilized in estimating the size of the target patient population are shown in Table 1. 
TABLE 2 Duration of Therapy and Treatment Summary Cost

\begin{tabular}{|c|c|c|c|c|c|}
\hline Parameter & Enzalutamide & $\begin{array}{c}\text { Abiraterone } \\
\text { Acetate }\end{array}$ & Sipuleucel-T & $\begin{array}{c}\text { Radium Ra } 223 \\
\text { Dichloride }\end{array}$ & Docetaxel \\
\hline Duration of therapy (months)a & $12.0(17.5)^{\mathrm{b}}$ & $12.0(13.8)^{\mathrm{c}}$ & 1.5 & 6.0 & 7.1 \\
\hline \multicolumn{6}{|l|}{ Drug cost/month } \\
\hline Dosed $^{\mathrm{d}}$ & $160 \mathrm{mg}$ & $1,000 \mathrm{mg}$ & 1 infusion & 1 vial & $75 \mathrm{mg} / \mathrm{m}^{2}$ \\
\hline Doses/month ${ }^{\mathrm{d}}$ & 30 & 30 & 2 & 1 & 1.43 \\
\hline Utilization/month & $4,800 \mathrm{mg}$ & $30,000 \mathrm{mg}$ & 2 infusions $^{e}$ & 1 vial & $225.2 \mathrm{mg}$ \\
\hline Cost/month (ASP + 4\%) & $\$ 8,355^{\mathrm{f}}$ & $\$ 7,377^{\mathrm{f}}$ & $\$ 68,515$ & $\$ 12,362^{f}$ & $\$ 1,030$ \\
\hline Administration cost/monthg & $\$ 0.00$ & $\$ 0.00$ & $\$ 151.06$ & $\$ 57.50$ & $\$ 108.01$ \\
\hline Pretreatment and concomitant medication cost/month & $\$ 0.00$ & $\$ 10.85$ & $\$ 0.16$ & $\$ 0.00$ & $\$ 11.75$ \\
\hline Monitoring cost/month & $\$ 0.00$ & $\$ 21.64$ & $\$ 0.00$ & $\$ 10.61$ & $\$ 28.28$ \\
\hline Adverse event cost/month & $\$ 162.09$ & $\$ 198.68$ & $\$ 1,022.35$ & $\$ 1,199.55$ & $\$ 562.33$ \\
\hline Total cost/month & $\$ 8,517$ & $\$ 7,608$ & $\$ 69,689$ & $\$ 13,630$ & $\$ 1,740$ \\
\hline Total treatment cost (12 months) & $\$ 102,204$ & $\$ 91,296$ & $\$ 104,534$ & $\$ 81,780$ & $\$ 12,354$ \\
\hline \multicolumn{6}{|c|}{$\begin{array}{l}\text { aDuration of therapy was based on the prescribing information of the respective therapies, with the exception of docetaxel (which was based on Tannock et al. } 200431 \text { ). } \\
\text { bCapped at } 12 \text { months because of the 1-year model time horizon; observed median duration of therapy in the clinical trial was } 17.5 \text { months. } \\
\text { cCapped at } 12 \text { months because of the 1-year model time horizon; observed median duration of therapy in the clinical trial was } 13.8 \text { months. } \\
\text { dDose and doses/month information was obtained from the prescribing information for each respective product. The leukapheresis procedure was included in the price of } \\
\text { the sipuleucel-T drug cost. } \\
\text { eUtilization/month for sipuleucel-T was based on 2-week dosing intervals as outlined in the prescribing information. Treatment duration was assumed to be } 1.5 \text { months to } \\
\text { account for a total of } 3 \text { doses. } \\
\text { fCost was based on wholesale acquisition cost because ASP was not available. }\end{array}$} \\
\hline
\end{tabular}

Treatment Cost and Duration. Dosing and duration of therapy for each comparator were based on the prescribing information for each respective product. Note that the duration of therapy for enzalutamide and abiraterone acetate was capped at 12 months (although observed median duration of therapy in clinical trials exceeded 12 months) because of the 1-year model time horizon (Table 2). Unit costs of comparator drugs were based on the Centers for Medicare \& Medicaid Services (CMS) average sales price (ASP) $+4 \%$ and wholesale acquisition cost (WAC) from RED BOOK when ASP was not available. ${ }^{19,20}$ Drug costs used in the model were current at the time of analysis (September 2014). Administration costs for infusion drugs included the cost of the infusion based on Medicare reimbursement for chemotherapy administration for a 1-hour infusion (Current Procedural Terminology code 96413). Inclusion of pretreatment and concomitant medication, as well as monitoring requirements, was determined based on the prescribing information for the respective therapies. Pretreatment and concomitant medication costs were based on ASP $+4 \%$ for physician-administered drugs and WAC from RED BOOK for oral drugs or when ASP was not available. ${ }^{19,20}$ Monitoring costs for complete blood count, hepatic function panel, and serum potassium assay tests were based on the CMS Clinical Diagnostic Laboratory Fee Schedule. Duration of therapy and treatment summary costs for each comparator is shown in Table 2.
Adverse Event Costs. Adverse event rates were obtained from the prescribing information and/or the pivotal trials for the respective comparators. Only grade 3 and 4 adverse events were included in the analysis. Adverse event costs were based on costs of hospitalization from the Healthcare Cost and Utilization Project Nationwide Inpatient Sample under the assumption that grade 3 and 4 events would require a hospitalization, consistent with the NCI Common Terminology Criteria for Adverse Events definitions. ${ }^{18,21}$ Appendix A contains a detailed list of included adverse events and associated Healthcare Cost and Utilization Project costs (available in online article).

Market Share. The market shares represent the percentage of health plan patients on each treatment regimen or total utilization of each treatment within the total population of patients being treated. However, because treatment cost components are estimated on a monthly basis and different treatment options require different durations, market shares were adjusted to reflect the percentage of treatment months. Use of percentage of treatment months normalizes the market share weight when using monthly cost components. New market shares are based on the assumption that increases in enzalutamide market share result in a reduction of the other product market shares proportionally to their current market share. The model assumed a 9\% enzalutamide market adoption at FDA approval of a chemotherapy-naive indication. Please refer to Appendix B for detailed market share information (available in online article). 


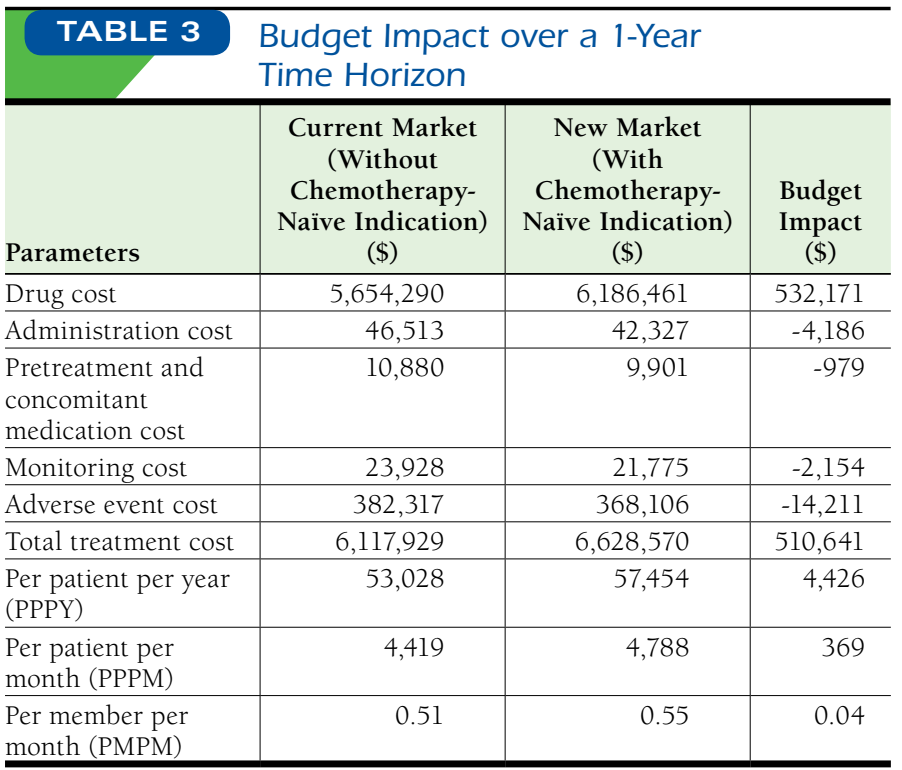

\section{Model Outputs}

Budget Impact. The budget impact analysis used the estimated costs modeled over the 1-year time horizon for payers to calculate the difference in costs between the new market (e.g., with chemotherapy-naive indication) and the current market (e.g., without chemotherapy-naive indication) for the chemotherapynaive populations in aggregate, per patient per year (PPPY), PPPM, and per member per month (PMPM) expenditures.

Sensitivity Analyses. To test the sensitivity of the model to variation in the model parameters, univariate sensitivity analyses were conducted for all key model parameters, with individual parameters being varied over a range from low to high based on increasing and decreasing the values by $10 \%$. The output for the 1-way sensitivity analysis was the budget impact with enzalutamide versus without enzalutamide.

\section{Results}

\section{Budget Impact Model: Base Case Analysis}

In the base case analysis, with 115 chemotherapy-naïve mCRPC patients in the plan population, adopting enzalutamide resulted in $\$ 510,641$ of additional total cost, $\$ 4,426$ PPPY, \$369 PPPM, and \$0.04 PMPM estimates. The potential budget impact over this 1-year time horizon is shown in Table 3. See Appendix C for supplemental data and additional results for scenario analyses (available in online article).

\section{Sensitivity Analysis}

The model results were most sensitive to the drug cost per month for enzalutamide, chemotherapy-naive mCRPC population size, and enzalutamide new market (percentage of chemotherapy-naive patients). The sensitivity analysis showed a maxi- mum expected budget impact of $\$ 614,746$ ( $\$ 0.05$ PMPM) when the enzalutamide drug cost was increased by $10 \%$. Results of the deterministic sensitivity analysis are shown in Figure 2.

\section{Discussion}

As a result of a growing and aging U.S. population, NCI projects that there will be 18.1 million cancer survivors by the year 2020, based on Surveillance, Epidemiology, and End Results (SEER) data and population projections from the U.S. Census Bureau. ${ }^{5}$ The overall cost of cancer care is expected to reach $\$ 157$ billion by 2020, representing a nearly 25\% increase from 2010 based on population changes alone. ${ }^{5}$ Similarly, the cost of prostate cancer care is expected to reach $\$ 15.1$ billion by the year 2020, up from $\$ 11.9$ billion in $2010 .^{5}$

The economic burden of metastatic prostate cancer has remained stable despite decreased hospital admissions, whereas utilization of hospice care has increased significantly. Hospital admissions for metastatic prostate cancer were shown to decrease at a rate of $-5.95 \%(P<0.001)$ per year between 1998 and 2010, while per incident charges increased at a rate of $6.1 \%(P<0.001)$ during the same time frame. ${ }^{22}$ Utilization of hospice increased $488 \%(P<0.001)$ per year and was associated with decreased odds of elevated hospital charges beyond the 75 th percentile (odds ratio $=0.84 ; P=0.02$ ) ${ }^{22}$

Given the high burden of prostate cancer, health care payers are interested in quantifying the potential budget impact of new therapies. We developed a model to estimate the annual budget impact of enzalutamide for the treatment of mCRPC from a U.S. third-party payer perspective. In a hypothetical plan of 1 million members, it was estimated that there would be approximately $115 \mathrm{mCRPC}$ patients without prior exposure to docetaxel (i.e., chemotherapy-naïve). Unlike other reported budget impact models in mCRPC, this model accounted for the costs of drug acquisition, administration, concomitant medication (corticosteroids), pretreatment medications, monitoring, and adverse events. The treatment duration of enzalutamide and abiraterone acetate reported from the clinical trial was capped at 12 months because of the 1-year model time horizon. In the chemotherapy-naive mCRPC population, enzalutamide resulted in $\$ 510,641$ of additional total cost, $\$ 4,426$ PPPY, $\$ 369$ PPPM, and \$0.04 PMPM, representing a modest budget impact. To our knowledge, this is the first analysis examining the budget impact of a treatment for chemotherapy-naive mCRPC with all currently available oncolytic medications being evaluated.

The results of the model reflect a lower cost of administration, monitoring, and adverse events associated with the use of enzalutamide compared with other treatment options. Despite an increase in overall drug acquisition cost, the treatment of chemotherapy-naive mCRPC patients with enzalutamide was predicted to result in a savings of $\$ 4,186$ in administration costs, $\$ 2,154$ in monitoring costs, and $\$ 14,211$ in adverse event costs over a 1-year time horizon. 
Enzalutamide-drug cost per month

Chemotherapy-naïve population

Enzalutamide-new market (\% patients)

Abiraterone acetone-drug cost per month

Enzalutamide-new market (\% patients)

Sipuleucel-T-drug cost per month

Docetaxel-drug cost per month

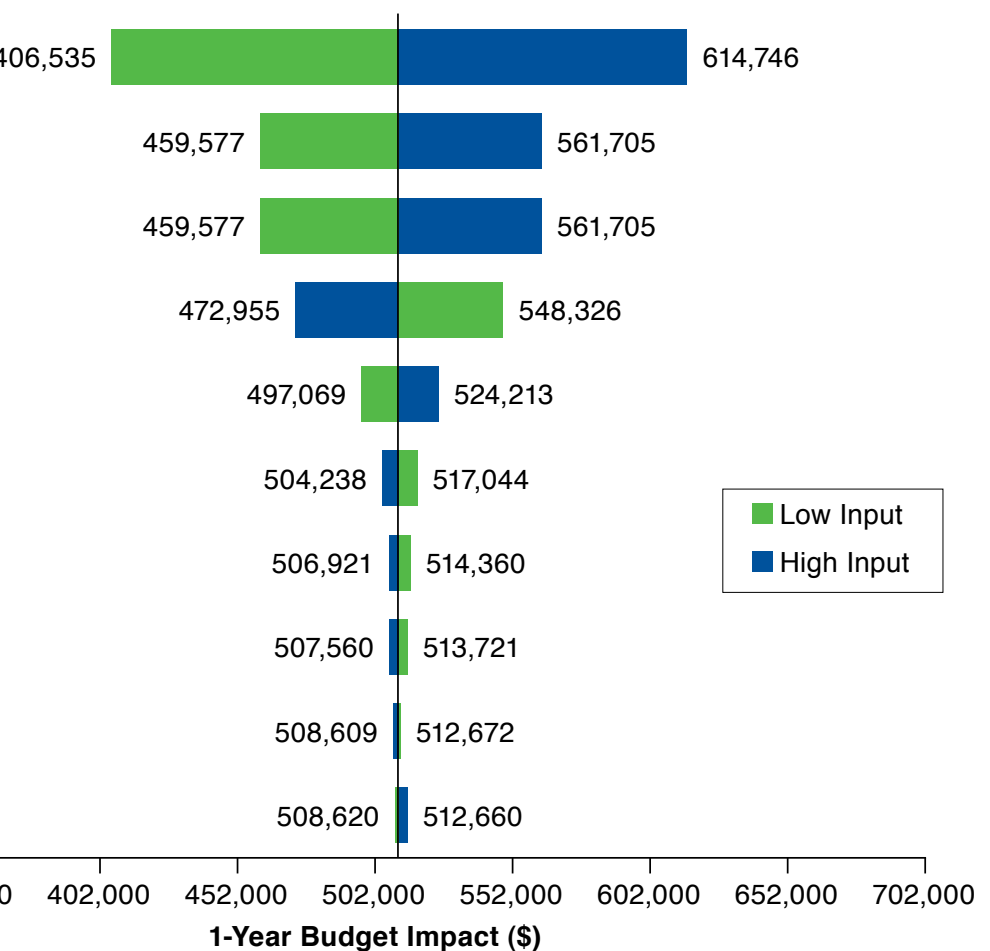

1-Year Budget Impact (\$)

Radium Ra 223 dichloride-drug cost per month

Docetaxel-adverse event cost per month

Enzalutamide-adverse event cost per month

Other pharmacoeconomic analyses have also sought to estimate the budget impact of therapy for mCRPC. For example, Sorensen et al. (2013) evaluated the annual budget impact of abiraterone acetate plus prednisone for MCRPC patients previously treated with docetaxel-based therapy. ${ }^{23}$ The analysis was conducted from a U.S. health plan perspective and based on a hypothetical 1-million-member plan, with an estimated 57 mCRPC patients previously treated with docetaxel. For a commercial plan, the study reported a PMPM impact range from $\$ 0.0019$ (with 8\% uptake) to $\$ 0.0133$ (with 55\% uptake). ${ }^{23}$ In a commercial plan with a subset of Medicare beneficiaries, the model estimated a PMPM range from $\$ 0.0026$ (with $8 \%$ uptake) to $\$ 0.0176$ (with $55 \%$ uptake). ${ }^{23}$ However, because the analysis utilized the same number of MCRPC patients previously treated with docetaxel in both the commercial and the commercial/Medicare scenarios, the model may have overestimated the number of cases in a commercial-only plan while underestimating the number of cases in the Medicare population. Cost offsets were attributed to lower adverse event costs with abiraterone acetate plus prednisone compared with chemotherapy-related costs. ${ }^{23}$ However, this study did not include treatment-monitoring costs associated with mCRPC therapy. ${ }^{23}$

Valderrama et al. (2014) evaluated 1-year incremental costs of treating patients with $\mathrm{mCRPC}$ with symptomatic bone metastases and no known visceral metastatic disease. ${ }^{24}$ The analysis was conducted from a U.S. health plan perspective and based on a hypothetical 1-million-member plan, with an estimated 220 patients eligible for treatment with radium Ra 223 dichloride. ${ }^{24}$ Adoption of radium $\mathrm{Ra} 223$ dichloride resulted in a PMPM budget impact of $\$ 0.02$ based on a $6.4 \%$ market uptake and an assumed cost of $\$ 11,500$ per 28 -day cycle. ${ }^{24}$ The model was most sensitive to the number of radium Ra 223 dichloride doses, according to sensitivity analyses. ${ }^{24}$

Hansen et al. (2013) estimated the budget impact of radium Ra 223 dichloride on expenses of a U.S. hospital-based infusion center. ${ }^{25}$ In a cohort of 1 million lives, an estimated 45 metastatic prostate cancer patients incurred approximately $\$ 500,000$ in treatment costs for current radiopharmaceuticals and chemotherapy agents..$^{25}$ Addition of radium Ra 223 dichloride to the treatment mix at an adoption rate of $1 \%-5 \%$ was predicted to result in an annual budget impact range of $\$ 600$ $\$ 3,000$ for a catchment area of 1 million lives. ${ }^{25}$

The potentially high cost of prostate cancer therapy has been a growing concern among payers. For example, sipuleucel-T, which was originally priced at $\$ 31,000$ per treatment, was approved by the FDA in April 2010 and subsequently covered by CMS for its FDA-approved indication. In the wake of the approval and national coverage decision for sipuleucel-T, 
the financial implications became a highly debated topic and brought to light broader health care issues, including payment reform and health care delivery models (such as accountable care organizations). ${ }^{26}$

Because the current report strictly concerns a budget impact model, the clinical effect of the respective therapies was not taken into account in our analysis. The clinical benefits of currently available mCRPC therapies, including reduction in disease progression and increased overall survival, also need to be considered to provide a more comprehensive analysis of these new treatment options.

\section{Limitations}

Although this model follows the currently established pharmacoeconomic standards and is transparent regarding the assumptions utilized in economic calculations, there remain limitations to our findings. ${ }^{15,16}$ Overall, the budget impact estimates are for a hypothetical 1-million-member health plan and may not be generalizable to other health plans. Results for an actual plan may differ based on differences in the population, costs, and market shares of treatments.

The present model included only grade 3 and 4 adverse events that were assumed to require hospitalization, with adverse event incidence rates based on prescribing information or pivotal trial data. Inclusion of grade 1 and 2 adverse events, particularly if protracted or bothersome to patients, might impact model results. Variation from the adverse event rates found in prescribing information or pivotal trials might impact the conclusions of this analysis as well. Likewise, a change in budget impact may be seen if hospitalization is not required.

Monitoring requirements and inclusion of pretreatment and concomitant medication were based on prescribing information for the respective therapies. Potential variation from prescribing recommendations in real-world practice would likely impact the budget impact presented in the base case analysis.

The present model does not account for the fact that some real-world patients are treated with a shorter duration of therapy and may initiate subsequent treatment (e.g., an additional line of therapy) after relapsing or not being able to tolerate prior treatment. The existing model assumes that patients are treated with $1 \mathrm{mCRPC}$ therapy at a time and does not account for the potential effect of prior or subsequent treatment(s) and combination regimens on current treatment duration and costs. This budget impact model does not capture the total cost of care, including the high cost of disease complications or progression such as skeletal-related events.

\section{Conclusions}

This budget impact analysis suggests that the adoption of enzalutamide in chemotherapy-naive mCRPC patients will have a modest budget impact to a hypothetical 1-millionmember health plan of $\$ 510,641$, with a PPPY of $\$ 4,426$, PPPM of $\$ 369$, and PMPM of $\$ 0.04$. The costs for enzalutamide were partially offset by moderate adverse event profile and concomitant medication costs as well as lack of additional monitoring requirements. Further research is necessary to validate the total direct costs of mCRPC in the real world.

\section{Authors}

CAT N. BUI, PharmD, MS, is Director, Global Health Economics and Outcomes Research, Oncology; SCOTT FLANDERS, PhD, is Director, Health Economics and Outcomes Research, Oncology; LINDA POSTA, PharmD, MBA, is Scientific Account Associate Director, Managed Markets and Health Economics and Outcomes Research; and HONG TANG, MD, FACP, is Senior Medical Director, Oncology, Astellas Pharma Global Development, Northbrook, Illinois. KEN O'DAY, PhD, MPA, is Director, Global Health Economics, and BREANNA POPELAR, PharmD, MS, is Manager, Global Health Economics, Xcenda, Palm Harbor, Florida. NINA OESTREICHER, PhD, is Assistant Clinical Professor, Department of Clinical Pharmacy, University of California, San Francisco. PETER FRANCIS, MD, is Medical Director, Medical Affairs, and MARK BALK, PharmD, MS, BCPS, is Regional Director, Medical Affairs, Medical Science Liaisons, Medivation, San Francisco, California.

AUTHOR CORRESPONDENCE: Cat N. Bui, PharmD, MS, One Astellas Way, South Mezzanine, Office 161, Northbrook, IL 60062.E-mail: cat.bui@astellas.com.

\section{DISCLOSURES}

The study and its report were funded by Astellas Pharma Global Development and Medivation, which had a role in study design, data acquisition and interpretation, and manuscript development. Xcenda is a consulting company that received fees from Astellas Pharma Global Development and Medivation to support this research, including model and manuscript development. Bui, Flanders, Posta, and Tang are current employees of Astellas. Francis and Balk are current employees and stockholders of Medivation. Oestreicher is a former employee of Medivation. O'Day and Popelar are current employees of Xcenda.

All authors contributed to the study concept and design, analysis and interpretation of data, and drafting and critical revision of the manuscript for important intellectual content. Bui and O'Day were responsible for acquisition of data. Bui obtained funding, and administrative, technical, or logistic support was provided by Bui and Popelar.

\section{ACKNOWLEDGMENTS}

The authors thank Shannon Davis and Sara Sloan of Infusion Communications for their assistance in manuscript preparation and figure creation, which was funded by Astellas Pharma Global Development and Medivation.

\section{REFERENCES}

1. Siegal RL, Miller KD, Jemal A. Cancer statistics, 2015. Cancer J Clin. 2015;65(1):5-29. 
2. National Cancer Institute and National Institutes of Health. Prostate cancer treatment (PDQ): stages of prostate cancer. Available at: http://www. cancer.gov/types/prostate/patient/prostate-treatment-pdq\#section/_120. Accessed November 20, 2015.

3. Solo K, Mehra M, Dhawan R, Valant J, Scher HI. Prevalence of prostate cancer (PC) clinical states (CS) in the United States: estimates using a dynamic progression model. J Clin Oncol. 2011;29(suppl):abstr 4637.

4. Scher HI, Morris MJ, Kelly WK, Schwartz LH, Heller G. Prostate cancer clinical trial end points: "RECIST"ing a step backwards. Clin Cancer Res. 2005;11(14):5223-32

5. Mariotto AB, Yabroff KR, Shao Y, Feuer EJ, Brown ML. Projections of the cost of cancer care in the United States: 2010-2020. J Natl Cancer Inst. 2011;103(2):117-28.

6. Stokes M, Ishak J, Proskorovsky I, Black LK, Huang Y. Lifetime economic burden of prostate cancer. BMC Health Serv Res. 2011;11:349.

7. Alemayehu B, Buysman E, Parry D, Becker L, Nathan F. Economic burden and healthcare utilization associated with castration-resistant prostate cancer in a commercial and Medicare Advantage U.S. patient population. J Med Econ. 2010;13(2):351-61.

8. National Comprehensive Cancer Network. NCCN clinical practice guidelines in oncology: prostate cancer. Version 1. Available at: http://www.nccn.org/professionals/physician_gls/f_guidelines.asp. Accessed November 20, 2015.

9. Hotte SJ, Saad F. Current management of castrate-resistant prostate cancer. Curr Oncol. 2010;17(Suppl 2):s72-79.

10. Tran C, Ouk S, Clegg NJ, et al. Development of a second-generation antiandrogen for treatment of advanced prostate cancer. Science. 2009;324(5928):787-90.

11. Scher HI, Fizazi K, Saad F, et al; AFFIRM Investigators. Increased survival with enzalutamide in prostate cancer after chemotherapy. N Engl J Med. 2012;367(13):1187-97.

12. Beer TM, Armstrong AJ, Rathkopf DE, et al; PREVAIL Investigators. Enzalutamide in metastatic prostate cancer before chemotherapy. N Engl J Med. 2014;371(5):424-33.

13. Tombal B, Miller K, Iversen P, et al. Enzalutamide in men with chemotherapy-naïve metastatic castration-resistant prostate cancer (mCRPC): updated overall survival analysis of the phase 3 PREVAIL study. Presented at: European Association of Urology; March 24, 2015; Madrid, Spain. Available at: http://data.uroweb.org/uploads/datal.eau.code.nl/eau_data_ webcasts/10352/file/index.html? playMax=NjA=\&stopUrl=http://rcmadrid2015.uroweb.org/buy-access/\&stopMessage $=$ To\%20view $\% 20$ the $\% 20$ entire $\% 20$ webcast, $\% 20$ you $\% 20$ need $\% 20$ to $\% 20$ login $\% 20$ to\%20MyEAU\%20 or\%20buy\%20access\%20to\%20Resource\%20Center\%20Madrid. Accessed November 20, 2015.

14. Academy of Managed Care Pharmacy (AMCP). The AMCP format for formulary submissions. Version 3.1. A format for submission of clinical and economic evidence of pharmaceuticals in support of formulary consideration. December 2012. Available at: http://amcp.org/practice-resources/ amcp-format-formulary-submisions.pdf.

15. Mauskopf JA, Sullivan SD, Annemans L, et al. Principles of good practice for budget impact analysis: report of the ISPOR Task Force on Good Research Practices-budget impact analysis. Value Health. 2007;10(5):336-47.

16. Sullivan SD, Mauskopf JA, Augustovski F, et al. Budget impact analysis-principles of good practice: report of the ISPOR 2012 Budget Impact Analysis Good Practice II Task Force. Value Health. 2014;17(1):5-14.

17. Sivanandam A, Siva S, Bhandari M, Menon M. Variance inflation in sequential calculations of body surface area, plasma volume, and prostatespecific antigen mass. BJU Int. 2008;102(11):1573-80.
18. National Cancer Institute, National Institutes of Health, and U.S. Department of Health and Human Services. Common terminology criteria for adverse events (CTCAE). Version 4.0. Published May 28, 2009 (v4.03: June 14, 2010). Available at: http://evs.nci.nih.gov/ftpl/CTCAE/ CTCAE_4.03_2010-06-14_QuickReference_5x7.pdf. Accessed November 20, 2015.

19. Centers for Medicare \& Medicaid Services. 2014 ASP drug pricing files. Available at: http://www.cms.gov/Medicare/Medicare-Fee-for-Service-Part-BDrugs/McrPartBDrugAvgSalesPrice/2014ASPFiles.html. Accessed November 20, 2015.

20. Truven Health Analytics, Micromedex Solutions. RED BOOK. A comprehensive, consistent drug pricing resource. 2014. Available at: http://micromedex.com/products/product-suites/clinical-knowledge/redbook. Accessed November 20, 2015.

21. Healthcare Cost and Utilization Project (HCUP). Welcome to H-CUPnet. Statistics on hospital stays. November 2015. Agency for Healthcare Research and Quality, Rockville, MD. Available at: http://www.hcupnet.ahrq.gov. Accessed December 9, 2015.

22. Sammon JD, McKay RR, Kim SP, et al. Burden of hospital admissions and utilization of hospice care in metastatic prostate cancer patients. Urology. 2015;85(2):343-9.

23. Sorensen S, Ellis L, Wu Y, Hutchins V, Linnehan JE, Senbetta M. Budgetary impact on a U.S. health plan adopting abiraterone acetate plus prednisone for the treatment of patients with metastatic castration-resistant prostate cancer. J Manag Care Pharm. 2013;19(9):799-808. Available at: http://www.amcp.org/JMCP/2013/Nov-Dec/17319/1033.html.

24. Valderrama A, Bilir SP, Wehler EA, et al. Estimating the economic impact of radium 223 dichloride (radium-223) in treatment of castrationresistant prostate cancer (CRPC) with symptomatic bone metastases and no known visceral metastatic disease. Presented at: ISPOR 19th Annual International Meeting; May 31-June 4, 2014; Montreal, Canada. Available at: http://www.ispor.org/research_study_digest/list.asp?qs=36087. Accessed November 20, 2015.

25. Hansen RN, Seal B, Wen L, et al. Estimating the budget implications of radium RA 223 dichloride in castration-resistant prostate cancer patients with non-visceral bone metastases treated in U.S. infusion centers. Presented at: ISPOR 16th Annual European Congress; November 2-6, 2013; Dublin, Ireland. Available at: http://www.ispor.org/RESEARCH_STUDY_ DIGEST/list.asp?qs=35347. Accessed November 20, 2015.

26. Chambers JD, Neumann PJ. Listening to Provenge-what a costly cancer treatment says about future Medicare policy. N Engl J Med. 2011;334(18):1687-89.

27. Howden LM, Meyer JA. Age and sex composition: 2010. 2010 Census Briefs. May 2011. Available at: http://www.census.gov/prod/cen2010/briefs/ c2010br-03.pdf. Accessed November 20, 2015.

28. Howlander N, Noone AM, Krapcho M, et al. Previous version: SEER cancer statistics review, 1975-2011. National Cancer Institute. Updated December 17, 2014. Available at: http://seer.cancer.gov/csr/1975_2011/. Accessed November 20, 2015.

29. Kirby M, Hirst C, Crawford ED. Characterising the castration-resistant prostate cancer population: a systematic review. Int J Clin Pract. 2011;65(11):1180-92.

30. Nakabayashi M, Hayes J, Taplin ME, et al. Clinical predictors of survival in men with castration-resistant prostate cancer: evidence that Gleason score 6 cancer can evolve to lethal disease. Cancer. 2013;119(16):2990-8.

31. Tannock IF, de Wit R, Berry WR, et al; TAX 327 Investigators. Docetaxel plus prednisone or mitoxantrone plus prednisone for advanced prostate cancer. N Engl J Med. 2004;351(15):1502-12. 


\section{APPENDIX A Adverse Event Cost from HCUP 2011}

\begin{tabular}{|c|c|c|c|c|c|c|}
\hline Event & $\begin{array}{l}\text { Adverse Event } \\
\text { Cost }^{\mathrm{a}} \\
(\$)\end{array}$ & $\underset{(\%)}{\text { Enzalutamide }}$ & $\begin{array}{c}\text { Abiraterone } \\
\text { Acetate } \\
(\%)\end{array}$ & $\begin{array}{c}\text { Sipuleucel-T } \\
(\%)\end{array}$ & $\begin{array}{c}\text { Radium Ra } 223 \\
\text { Dichloride } \\
(\%)\end{array}$ & $\begin{array}{c}\text { Docetaxel } \\
(\%)\end{array}$ \\
\hline Allergic reaction & 7,013 & & & & & 1.0 \\
\hline ALT increased ${ }^{b}$ & 6,198 & 5.0 & & & & \\
\hline Anemia & 8,750 & & & 1.8 & 6.0 & 5.0 \\
\hline Anorexia & 7,435 & & & 0.2 & 2.0 & 1.0 \\
\hline Arthralgia & 6,299 & 1.6 & & 1.8 & & 1.0 \\
\hline AST increased ${ }^{b}$ & 6,198 & & 3.0 & & & \\
\hline Back pain & 7,186 & 2.5 & & 3.0 & & \\
\hline Bone pain & 10,693 & & & 0.7 & 21.0 & \\
\hline Cardiac disorder ${ }^{b}$ & 11,394 & & 6.0 & & & \\
\hline Chills & 5,194 & & & 2.2 & & \\
\hline Constipation & 6,101 & 0.7 & 0.4 & 0.2 & 1.0 & \\
\hline Decreased appetite & 7,435 & 0.3 & & & & \\
\hline Diarrhea & 7,177 & 0.3 & 0.9 & 0.2 & 2.0 & 2.0 \\
\hline Dizziness & 5,566 & 0.3 & & 0.3 & 0.5 & \\
\hline Dysgeusia & - & 0.1 & & & & \\
\hline Dyspnea & 6,644 & 0.6 & 2.4 & 1.8 & 3.0 & 3.0 \\
\hline Edema & 6,075 & & 0.4 & 0.2 & 2.0 & 1.0 \\
\hline Fall & - & 1.6 & & & & \\
\hline Fatigue/asthenia & 6,438 & 3.4 & 2.2 & 2.0 & 1.0 & 5.0 \\
\hline Fracture & 16,209 & 2.1 & & & 2.0 & \\
\hline Groin pain & 6,390 & & 0.4 & & & \\
\hline Headache & 6,033 & 0.2 & & 0.7 & & \\
\hline Hematuria & 7,534 & 1.3 & 1.3 & 1.0 & 1.0 & \\
\hline Hot flush & 5,927 & 0.1 & 0.2 & 0.3 & & \\
\hline Hypertension $^{\mathrm{b}}$ & 8,308 & 7.2 & 3.9 & 0.5 & & \\
\hline Hypokalemia & 6,274 & & 2.0 & & & \\
\hline Infection & 8,410 & & & & 10.0 & 6.0 \\
\hline Insomnia & 4,491 & 0.1 & 0.2 & 0.0 & 0.0 & \\
\hline Joint swelling/ discomfort & 6,555 & & 2.0 & & & \\
\hline Leukopenia & 9,101 & & & & 3.0 & \\
\hline Lower respiratory tract infection & 10,005 & 1.5 & & & & \\
\hline Lymphocytopenia & - & & & & 20.0 & \\
\hline Muscle discomfort & 7,401 & & & 0.5 & & \\
\hline Muscle spasms & 7,314 & & & 0.3 & & \\
\hline Muscle weakness & 8,424 & & & & 1.0 & \\
\hline Nausea & 5,710 & & & 0.5 & 2.0 & 3.0 \\
\hline Neck pain & 6,781 & & & 0.5 & & \\
\hline Neutropenia (febrile) & 16,266 & & & & 0.5 & \\
\hline Neutropenia (afebrile) & 4,150 & & & & 2.0 & 32.0 \\
\hline Pain & 10,343 & & & 1.2 & & \\
\hline Pancytopenia & 10,981 & & & & 1.0 & \\
\hline Paresthesia & 6,044 & & & 0.2 & & \\
\hline Peripheral edema & 6,075 & 0.2 & & & & \\
\hline Peripheral neuropathy & 9,103 & & & & & 4.0 \\
\hline Pneumonia & 10,086 & & & & 3.0 & \\
\hline Pyrexia & 6,553 & & 0.6 & 1.0 & 1.0 & \\
\hline Renal impairment & 10,167 & & & & 1.0 & \\
\hline Restless leg syndrome & 5,034 & 0.1 & & & & \\
\hline Seizureb & 6,851 & 0.1 & & & & \\
\hline Spinal cord compression & 15,709 & & & & 3.5 & \\
\hline Stomatitis/pharyngitis & 6,819 & & & & & 1.0 \\
\hline Sweating & 5,796 & & & 0.2 & & \\
\hline Tearing & - & & & & & 1.0 \\
\hline Thrombocytopenia & 9,394 & & & & 3.0 & 1.0 \\
\hline Urinary retention & 6,225 & & & & 2.0 & \\
\hline Urinary tract Infection & 6,957 & & & 0.2 & 1.0 & \\
\hline Vomiting & 4,594 & & & 0.3 & 2.0 & 2.0 \\
\hline Weight decreased & 8,700 & 0.8 & 0.3 & & 1.0 & \\
\hline
\end{tabular}


APPENDIX B Market Shares

\begin{tabular}{l|c|c}
\hline Drug & $\begin{array}{c}\text { Current Market } \\
(\%)\end{array}$ & $\begin{array}{c}\text { New Market } \\
\text { (\%) }\end{array}$ \\
\hline Enzalutamide & 0.0 & 9.0 \\
\hline Abiraterone acetate & 41.0 & 37.3 \\
\hline Sipuleucel-T & 6.0 & 5.5 \\
\hline $\begin{array}{l}\text { Radium Ra 223 } \\
\text { dichloride }\end{array}$ & 4.0 & 3.6 \\
\hline Docetaxel & 49.0 & 44.6 \\
\hline
\end{tabular}

${ }^{a}$ New market shares for competitor products were based on the assumption that market adoption of enzalutamide corresponded with a reduction in market shares of other products in proportion to their current market share. 


\section{APPENDIX C Supplemental Data: Scenario Analysis}

Scenario: Population Aged $\geq 65$ Years (437 Chemotherapy-Naive mCRPC Patients)

In a scenario in which all hypothetical plan members are assumed to be aged $\geq 65$ years, such as a Medicare population, the budget impact of enzalutamide would increase driven by an increased incidence of mCRPC. Assuming that $100 \%$ of the plan population is aged $\geq 65$ years results in 437 chemotherapynaive $\mathrm{mCRPC}$ patients and a budget impact to the health plan of $\$ 1,934,574$, with a PPPY of $\$ 4,426$, PPPM of $\$ 369$, and PMPM of $\$ 0.16$.

\begin{tabular}{|c|c|c|c|}
\hline Parameters & $\begin{array}{l}\text { Current Market } \\
\text { (Without Chemotherapy-Naive } \\
\text { Indication) } \\
(\$)\end{array}$ & $\begin{array}{c}\text { New Market } \\
\text { (With Chemotherapy-Naïve } \\
\text { Indication) } \\
(\$)\end{array}$ & $\begin{array}{c}\text { Budget Impact } \\
(\$)\end{array}$ \\
\hline Drug cost & $21,421,408$ & $23,437,550$ & $2,016,142$ \\
\hline Administration cost & 176,216 & 160,356 & $-15,859$ \\
\hline Pretreatment and concomitant medication cost & 41,219 & 37,509 & $-3,710$ \\
\hline Monitoring cost & 90,653 & 82,494 & $-8,159$ \\
\hline Adverse event cost & $1,448,418$ & $1,394,579$ & $-53,840$ \\
\hline Total treatment cost & $23,177,913$ & $25,112,488$ & $1,934,574$ \\
\hline Per patient per year (PPPY) & 53,028 & 57,454 & 4,426 \\
\hline Per patient per month (PPPM) & 4,419 & 4,788 & 369 \\
\hline Per member per month (PMPM) & 1.93 & 2.09 & 0.16 \\
\hline
\end{tabular}

Scenario: Population Aged $<65$ Years (35 Chemotherapy-Naive mCRPC Patients)

In a scenario in which all hypothetical plan members are assumed to be aged $<65$ years, the budget impact of enzalutamide would decrease driven by a decreased incidence of mCRPC. Assuming that $100 \%$ of the plan population is aged $<65$ years results in 35 chemotherapy-naïve mCRPC patients and a budget impact to the health plan of $\$ 154,657$, with a PPPY of $\$ 4,426$, PPPM of $\$ 369$, and PMPM of $\$ 0.01$.

\begin{tabular}{|c|c|c|c|}
\hline Parameters & $\begin{array}{l}\text { Current Market } \\
\text { (Without Chemotherapy-Naïve } \\
\text { Indication) } \\
(\$)\end{array}$ & $\begin{array}{c}\text { New Market } \\
\text { (With Chemotherapy-Naive } \\
\text { Indication) } \\
(\$)\end{array}$ & $\begin{array}{c}\text { Budget Impact } \\
(\$)\end{array}$ \\
\hline Drug cost & $1,712,511$ & $1,873,689$ & 161,178 \\
\hline Administration cost & 14,087 & 12,820 & $-1,268$ \\
\hline Pretreatment and concomitant medication cost & 3,295 & 2,999 & -297 \\
\hline Monitoring cost & 7,247 & 6,595 & -652 \\
\hline Adverse event cost & 115,792 & 111,488 & $-4,304$ \\
\hline Total treatment cost & $1,852,933$ & $2,007,590$ & 154,657 \\
\hline Per patient per year (PPPY) & 53,028 & 57,454 & 4,426 \\
\hline Per patient per month (PPPM) & 4,419 & 4,788 & 369 \\
\hline Per member per month (PMPM) & 0.15 & 0.17 & 0.01 \\
\hline
\end{tabular}

Scenario: Pharmacy Cost Only (115 Chemotherapy-Naïve mCRPC Patients)

In a scenario that includes pharmacy cost only (e.g., excluding administration, pretreatment and concomitant medication, monitoring, and adverse event costs), the budget impact of enzalutamide is greater because of the lack of cost offsets. Inclusion of pharmacy cost only results in a budget impact to the health plan of $\$ 532,171$, with a PPPY of $\$ 4,613$, PPPM of $\$ 384$, and PMPM of $\$ 0.04$.

\begin{tabular}{|c|c|c|c|}
\hline Parameters & $\begin{array}{l}\text { Current Market } \\
\text { (Without Chemotherapy-Naive } \\
\text { Indication) } \\
(\$)\end{array}$ & $\begin{array}{c}\text { New Market } \\
\text { (With Chemotherapy-Naïve } \\
\text { Indication) } \\
(\$)\end{array}$ & $\begin{array}{c}\text { Budget Impact } \\
(\$)\end{array}$ \\
\hline Drug cost & $5,654,290$ & $6,186,461$ & 532,171 \\
\hline Administration cost & 0 & 0 & 0 \\
\hline Pretreatment and concomitant medication cost & 0 & 0 & 0 \\
\hline Monitoring cost & 0 & 0 & 0 \\
\hline Adverse event cost & 0 & 0 & 0 \\
\hline Total treatment cost & $5,654,290$ & $6,186,461$ & 532,171 \\
\hline Per patient per year (PPPY) & 49,009 & 53,622 & 4,613 \\
\hline Per patient per month (PPPM) & 4,084 & 4,468 & 384 \\
\hline Per member per month (PMPM) & 0.47 & 0.52 & 0.04 \\
\hline
\end{tabular}

$m C R P C=$ metastatic castration-resistant prostate cancer 